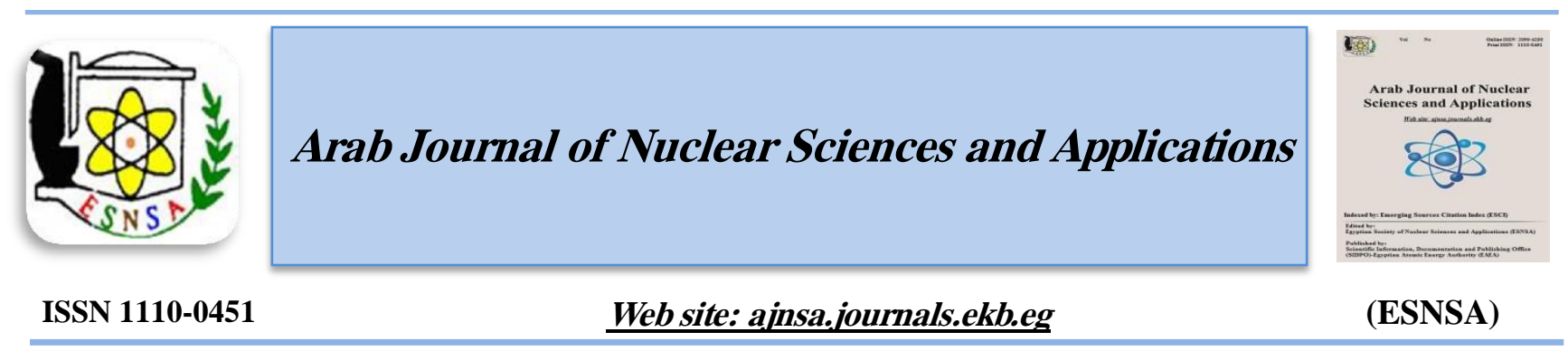

\title{
The Models Used in Predicting Steam Condensation Occuring during Nuclear Reactor Loss of Coolant Accident
}

\author{
Adel Lotfy Ismail \\ Reactors Department, Nuclear Research Center, Atomic Energy Authority, Cairo, 13759 Egypt
}

\begin{abstract}
Received $2^{\text {nd }}$ Dec. 2018 The aim of the present study is to review and compare between the methodologies used for modeling Accepted $12^{\text {th }}$ Dec. 2019 condensation with non-condensable, in a two-phase flows channel. The important state-of-the art numerical algorithms for the solution of multi-phase conservation equations are reviewed. The methodology for modeling condensation in these algorithms is based on the stagnant film theory. The methodology used in RELAP5/MOD3 was the most accurate model because it rigorously treats the coupling between the heat and mass transfer processes, and the gas-liquid interphase without iteration.
\end{abstract}

Keywords: Modeling / Condensation / LOCA

\section{Introduction}

Condensation of two-phase systems in channel flow takes place in certain nuclear reactor accidents. For example, during a small-break lossof-coolant accident (LOCA) in pressurized water reactor, following the partial depletion of the primary coolant, condensation of steam on the primary side of the steam generator tubes can provide a heat sink for disposal of decay heat generated in the reactor core. Condensation of twophase systems can also play an important role in the operation of the passive emergency cooling system in the advanced boiling water reactor.

Non-condensable gases, even in small quantities, are known to significantly reduce the heat transfer and condensation rate. Condensation in the presence of non-condensable gases has recently been studied because of its application in the design and operation of various modern heat transfer systems including Channel flow configurations, which has been recently studied experimentally. Because of the complexity of the analysis, analytical models, are generally scarce. The current work reviews the previous theoretical and experimental studies for condensation with non-condensable gases in two phase flow after LOCA occurred in reactors.

Review of previous theoretical and experimental work

Since the first significant advance in pure steam condensation addressed by Nusselt [1], a large number of theoretical and experimental investigations have been performed to determine the overall heat transfer coefficient (HTC) of steam in the presence of non-condensable gases.

The most widely used correlation for predicting the condensation inside a nuclear plant containment building following a LOCA is based on the experimental work of Uchida et al.[3] and Tagami [3] because of its simplicity and conservative nature. Uchida's correlation takes the form:

$$
h_{\text {Uchida }}=379\left(m_{g} / m_{s}\right)^{-.707} \text { for }\left(m_{g} / m_{g}\right)
$$

Corresponding author: sazm4@yahoo.com

DOI: 10.21608 /ajnsa.2019.6413.1146

(C) Scientific Information, Documentation and Publishing Office (SIDPO)-EAEA 


$$
h_{\text {Tagami }}=11.4+284\left(m_{s} / m_{g}\right)
$$

Their experiments were performed in the same experimental apparatus and studied condensation in the presence of a non-condensable gases onto a vertical cylinder $64 \mathrm{~cm}$ in circumference and either $30 \mathrm{~cm}$ (Uchida [2] \& Tagami [3]) or $90 \mathrm{~cm}$ (Tagami) high. The non-condensable gases studied were air, nitrogen and argon. The experiments took place in a constant volume enclosure $\left(-45 \mathrm{~m}^{3}\right)$, with the initial pressure of non-condensable gas being approximately one atmosphere.

Since the middle of the 1970s, efficient solution methods have been available for two-phase flow modeling. Several computer codes, based on these methods have been developed and most of them were for safety analysis of nuclear reactors. Some example are: TRAC-BD1[4]; RETRAN-03 [5]; and the latest two versions of the RELAP5 code, namely RELAP5/MOD2[6] and RELAP5/MODE3 [7]. These codes generally apply semi-implicit finite differencing, and use donor-cell formulation. The algorithms used in various codes are different from each other. The difference between their numerical algorithms depends on terms in the governing equations, which are explicitly or implicitly integrated, and on how the resulting nonlinear equations are solved.

Gido and Koestel [8] published a study which was critical of using the Uchida \& Tagami curve fits for predicting containment condensation. They pointed out that maximum condensation rates predicted by Uchida \& Tagami's correlations are significantly lower than those obtained in the Carolinas Virginia Tube Reactor containment tests, where the containment surface is much larger and longer than in Uchida's apparatus. The relatively small size of the Uchida test assembly is suspected as the primary cause for this discrepancy. In addition the Gido \& Koestel correlations were derived for a natural convection and a forced convection cases.

Dehbi [9] performed numerical and experimental studies in an attempt to predict turbulent boundary layer condensation. The author draws attention to the fact that the models based on the heat/mass transfer analogy generally underestimate the rate of turbulent natural convection condensation. Dehbi performed external condensation Arab J. Nucl. Sci. \& Applic. Vol. 53, No. 1 (2020) experiments on a $3.8 \mathrm{~cm}$ diameter, 3.5 meter vertical cylinder suspended in a pressure vessel. Steam-air mixtures were studied for pressures of $1.5,3.0$ and 4.5 atmospheres with air mass fractions ranging from 0.25 to 0.9 . Steam-airhelium mixtures were studied for pressures of 2.7 to 3.5 atmospheres and mass fractions of helium at $0.017,0.047$ and 0.083 .

Corradini [10] developed a model to predict heat transfer between steam-air atmospheres and cool walls which considers both sensible and latent heat transfer. The overall heat transfer coefficient is assumed to consist of two resistances in seriesnamely, that due to energy transfer through the condensate film and that due to energy transfer ( diffusion) through the gas-vapor boundary layer, The heat transfer coefficient through the gas-steam mixture accounts for two energy transfer processes- convection and condensation. The Corradini model was derived for both forced and natural convection. It has been compared against several experiments with good results for average heat transfer rates.

Peterson [11] developed a turbulent diffusion model for natural convection flow which allows for the calculation of local heat transfer coefficients for both the condensation and convection processes in terms of saturation temperature differences. Those coefficients are then used in conjunction with a condensate film heat transfer coefficient from a relevant film model to predict overall heat transfer in a method similar to that used in the Corradini model. The condensation heat transfer coefficient is based on the definition of a condensation thermal conductivity, which allows smooth integration of the heat/mass transfer analogy into the formulation. Peterson's model was based on the experimental programs carried out in an attempt to produce a theoretical basis for describing noncondensable gas effects on condensation.

Peterson also applied this model to the conditions of the Uchida experiments. He found that the Uchida correlation will overestimate heat removal for containment conditions where the noncondensable gas partial pressure is less than one atmosphere and underestimate where the noncondensable gas partial pressure is more than one atmosphere (the usual situation inside a postLOCA containment). Both models give close 
prediction of average condensation heat transfer coefficients which are in good agreement with most published experimental data. The major drawbacks of these two models are their complexity and the number of iterations that may be required at each time step in order to predict the correct interface temperature.

The only phenomenon that is usually added to the classical Nusselt formulation of liquid film heat transfer coefficient (HTC) is related to the structure of the surface. From almost the beginning of condensation, a wave structure is set up onto the condensate surface, which enhances the heat transfer. This modification at the interface appears from Reynolds number of 30 (Mills) [12], which is a very low value. From the phenomenological point of view, the inertia forces create instabilities whose fundamental consequence is a higher homogeneity in the difference of temperature, which can be interpreted in twofold-: namely, as a reduction in the effective thickness of the thermal resistance, or as a decrease in the difference of temperatures produced. Another relevant consequence is the increase in the interface area. These two factors cause an improvement in the HTC.

Mills [12] developed specific formulations for the Nusselt liquid number in order to account for the HTC increase when the Reynolds number is higher than 30. The same result is found in Kang and Kim [13] and also in Kim and Corradini [14], where an enhancement of $10 \%$ of the total HTC is experimentally obtained. From the gas side, its importance is even higher, to such an extent of restricting the influence of the wavy surface regarding only the modification on the gas diffusion thermal resistance.

The experimental effect found by Karapantsios et al.[15] consists of a thicker gas diffusion boundary layer produced by the liquid waves, which originated a momentum transfer from the liquid to the gas. This has already been analytically studied by Koh et al [16] in the case of a quiescent vapor is difficult to explain, even contradicting the results showed by Park et al [17] where an increasing of the gas HTC is found with a higher Reynolds liquid number the waves disturb the noncondensable barrier.
However, the Karapantsios results [15] are not relevant since the containment gas flux is not quiescent, being the buoyancy force high enough to neglect this possible negative effect, Fox et al [18] found Froude numbers of 0.04 , even with a high power jet.

Different authors (Herranz et al [19] Mu nozCobo et al [20] ) treat this phenomenon by means of a factor which is constant or a function that depends on the Reynolds number,always producing an increase in the HTC.

Condensate film represents one of the key points where a total disagreement is found. This disagreement is especially caused mainly by the specific boundary conditions in the experimental facility where the relative contribution of the thermal resistance to the HTC is analyzed.

All authors agree in the following important points: on one hand, the presence of noncondensable makes the diffusion process controlled; on the other hand, the liquid temperature is very close to the wall temperature, to the point that for a non-condensable mass fraction of only 2\%, Green and Almenas [21] analytically, and Murase et al [22] experimentally, state the liquid thermal resistance relative contribution up to a 5\%, and the jump of temperatures in only $0.4-{ }^{\circ} \mathrm{C}-$ Bunker and Carey [23] in $1^{\circ} \mathrm{C}$ - concluding that for values where $\eta \sim 1$ $\left(w_{n c}, w_{s t}\right)$ and HTC lower than $2 \mathrm{~kW} / \mathrm{m}^{2} \mathrm{~K}$, as it usually happens in the containment, the thermal resistance will still be lower than a $5 \%$ relative contribution.

More recently, Malet et al [24] performed an analytical study of the TOSQAN facility experimental results. The authors calculated the interfacial temperature value by means of the Uchida correlation and the Nusselt film thickness formulation, corrected by a wave structure factor. The results yielded a maximum temperature difference with respect to that of the wall of $0.4{ }^{\circ} \mathrm{C}$, so similar to the Murase [22] measured value. In spite of this negligible value, especially if comparing this value to the possible errors due to the wall conductivity heat transfer or the ambient heat losses, the authors limited the possible consequences of these results, saying that in different situations this value could be higher. 
In many publications (Whitley et al [25], Corradini [10]), an exact model is compared with one in which the liquid thermal resistance is neglected, showing that both models yield almost the same values. It is important to account for that, since Slegers and Seban [26] pointed out, several experimental studies (Hampson [28], Meisenburg et al. [28]) which showed a value for the condensate HTC (without non-condensables) 20\% higher than the one obtained from the Nusselt formulation.

This means that if the condensate thermal resistance is neglected because of the high value of its HTC, its real value is even higher, which would confirm the negligible importance of the condensate thermal resistance. The LHTC (liquid heat transfer coefficient) calculated values by Corradini [10] are closer to $4-5 \mathrm{~kW} / \mathrm{m} 2 \mathrm{~K}$, while the usual values of the HTC are lower than 1 $\mathrm{kW} / \mathrm{m}^{2} \mathrm{~K}$ (for values of $\eta \sim 1$ ). Most of the authors neglect the condensate thermal resistance (Fox et al [18] Bunker and Carey [23], Whitley et al [25] Slegers and Seban [26], Huhtiniemi and Corradini[29]), trend that to date is maintained, and even stressed.

The reasons that are used to be held in order to consider the condensate thermal resistance are related with an increasing of the GHTC (gas heat transfer coefficient) owing to the important influence of the gas velocity regarding HTC (Kim and Corradini [14]), because the LHTC can considerably decrease with a long condensate surface5 (Herranz et al.[19], Murase et al.[23]), or because the wall temperature can increase to such a high value where it will be important to consider the temperature difference between wall and interface. At the same time, there are several effects that are not considered in the Nusselt liquid film theory, which can increase the heat transfer through the liquid film; among them, the wavy surface of the film, the turbulence that can be established when the condensate length is high, or the momentum transfer from the condensate gas to the liquid that produces a shrinkage of the film (suction effect over the liquid) (Corradini [10]).

Kang and Kim [13] found also experimentally a relationship between LHTC and GHTC from 2 to 10 for liquid velocities of $3 \mathrm{~m} / \mathrm{s}$ and air mass fraction of $41 \%$, when the Reynolds liquid number changed from 0 to 10000 . When the mass fraction was $78 \%$, this relationship changed from 3 to 100 . Summing up, before not considering the liquid thermal resistance, it has to be demonstrated that is negligible for the real containment conditions (natural circulation, high wall length, possible turbulence of gas and liquid, and real value of the difference of temperatures between bulk and wall).

Arijit Ganguli et al.[30] Had an important work emphasized on the issue that modeling the diffusion of water-vapor through the gas-liquid interface to give good predictions in overall heat transfer coefficient. Therefore, modifications had been made in the derivation for calculation of condensation conductivity in the case of steam-air mixture and effective diffusivity (in the case of multicomponent mixture). The model validation had been done with experimental data. Condensation of steam coming out from the coolant pipe during a loss of coolant accident (LOCA).

Mehdi Dehjourian et al.[31] had computer code which can simulate the progression of severe accidents postulated for light water reactors. This code is used to treat the entire spectrum of severe accident phenomena, including thermal-hydraulic response in a reactor coolant system and containment, core heat-up, degradation and relocation, and fission product release and transport, in a unified framework for both PWR and boiling water reactor.

Xiaomin $\mathrm{Wu}$ et al [32] had experimentally investigated to $\mathrm{R} 11$ free convection film condensation heat transfer on a horizontal tube outside surface in the presence of three noncondensable gases, $\mathrm{N}_{2}, \mathrm{CO}_{2}$ and $\mathrm{R} 22$, whose molecular weights are all smaller than that of R11. The results show that the heat transfer is sharply reduced at very low gas concentrations with smaller reductions at increasing gas concentrations. The condensation heat transfer reduction due to the gases with ${ }^{M_{n c}}<M_{v}$ (where $M$ is molecular weight) is much stronger than that with $M_{n c}>M_{v}$ at low gas concentrations. The reductions for the two types of gases get closer with increasing gas concentrations. A heat transfer correlation had developed with $95 \%$ of the predictions within $\pm 20 \%$ of the experimental data. Experiments of refrigerant film condensation on a 
horizontal tube were conducted. The predictions by the correlation agreed well with the experimental data. The three non-condensable gases all significantly reduced the condensation heat transfer. A heat transfer correlation was developed with $95 \%$ of the experimental data within $\pm 20 \%$ of the predictions. The effect of the non-condensable gases on the free convection film condensation heat transfer when the molecular weights of the gases are less than that of the vapor is much stronger than when the molecular weights of the gases are greater than that of the vapor. The reductions for both types of non-condensable gases get closer with increasing gas concentration.

Guangming Fan et al.[33] development a new empirical correlation for steam condensation rates in the presence of air outside vertical smooth tube depending on discuses several works, experimentalists have proposed a large number of correlations to estimate steam condensation rates in the presence of non-condensable gases within free convection regime. He found that these correlations are in different forms, and even express conflicting dependencies of the condensation coefficient on some parameters. The study is aim to developing a new correlation which can faithfully reflect the complex dependencies of condensation coefficient on pressure, air mass fraction and wall sub-cooling. Total 374 sets of experimental data can certainly help to analyze the relationship between condensation coefficient and these parameters. It is found that there is a negative

Table 1: Review of containment-specific steam condensation HTC $^{(34)}$

\begin{tabular}{|c|c|c|}
\hline S. no. & Name & Equation \\
\hline 1 & Uchida & $h=379^{\left(m_{s} / m_{s}\right)^{-0.707}}$ for $\left(m_{s} / m_{s}\right)<20, h\left(\mathrm{~W} / \mathrm{m}^{2}\right)$ \\
\hline 2 & Tagami steady state & $h=11.4+284(\eta /(1-\eta)), \mathrm{h}\left(\mathrm{W} / \mathrm{m}^{2}\right)$ \\
\hline 3 & Debhi & $\begin{array}{l}h=\mathrm{L}^{0.05}[(3.7+28.0 \mathrm{P})-(243.8+458.3 \mathrm{P}) \log \eta] /\left(\left(T_{b}-T_{\mathrm{W}}\right)^{0.25}\right) \\
h\left(\mathrm{~W} / \mathrm{m}^{2}\right), \mathrm{P}(\mathrm{Atm}), \mathrm{L}(\mathrm{m}), T(\mathrm{~K})\end{array}$ \\
\hline 4 & Kataoka & $h=430 \eta^{-0.8}, h\left(\mathrm{~W} / \mathrm{m}^{2}\right)$ \\
\hline 5 & Murase & $h=0.47 \eta^{-1.0}, h\left(\mathrm{~W} / \mathrm{m}^{2}\right)$ \\
\hline 6 & $\begin{array}{l}\text { Liu (Lee and Kim, } \\
2008 \text { ) }\end{array}$ & $h=55.635(1-\eta)^{2.344} \mathrm{P}^{0.252}\left(\left({ }^{T_{b}-T_{w}}\right)^{0.307}\right),{ }^{h}\left(\mathrm{~W} / \mathrm{m}^{2}\right), \mathrm{P}(\mathrm{Pa}),{ }^{T}(\mathrm{~K})$ \\
\hline 7 & $\begin{array}{l}\text { Green (Green and } \\
\text { Almenas, } 1996)\end{array}$ & $h=316 \eta^{-0.86}\left(\left(T_{b}-T_{w}\right)^{-0.15}\right), \quad h\left(\mathrm{~W} / \mathrm{m}^{2}\right), \mathrm{T}(\mathrm{K})$ \\
\hline 8 & $\begin{array}{l}\text { Kawakubo } \\
\text { (Kawakubo et al., } \\
\text { 2009) }\end{array}$ & $\begin{array}{l}h=\min \left(0.33 \eta^{-0.8} \times\left(T_{b}-T_{w}\right)^{0.25}, \eta^{-1.0} \times\left({ }^{T_{b}-T_{w}}\right)^{-0.22} \eta\right) \times(\mathrm{P}+0.5), \\
h\left(K w / m^{2}\right), P(M P a) \\
h=f_{1} \times f_{2} \times h_{\text {mussel }} \text { where } f_{2}=\left(1+2.88 E^{-05} \mathrm{Re}_{m i x}^{1.18}\right) \text { and a maximum fixed } \\
\text { value of } 2.0 \text { is used in } \operatorname{Pavan}^{(34)} \text { paper. } h\left(\mathrm{~W} / \mathrm{m}^{2}\right)\end{array}$ \\
\hline 9 & $\begin{array}{l}\text { Nusselt } \\
\text { Multiplier } \\
\text { al., } 1999)\end{array}$ & $\begin{array}{l}h_{\text {musselt }}=k_{f} / \delta \text { and } f_{2}=(1-10.0 \eta) \text { for } \eta<0.063 \\
f_{2}=\left(1-0.938 \eta^{0.13}\right) \text { for } 0.063<\eta<0.6 \\
f_{2}=\left(1-\eta^{0.22}\right) \text { for } \eta>0.6\end{array}$ \\
\hline 10 & $\begin{array}{l}\text { Nusselt LEE } \\
\text { Multiplier (Lee and } \\
\text { Kim, 2008) }\end{array}$ & $\begin{array}{l}h=f_{\text {lee }} \times h_{\text {mussel }} \text { where } \\
h=f_{\text {lee }} h_{\text {masselt }}=k_{f} / \delta \text { and } f_{\text {lee }}=\tau_{\text {mix }}^{0.3124} \text { flee }=\tau \operatorname{mix} 0.3124(1-0.964 \eta 0.402), \\
\mathrm{h}\left(\mathrm{W} / \mathrm{m}^{2}\right)\end{array}$ \\
\hline
\end{tabular}


power function relation between condensation coefficient and wall sub-cooling, and the exponent varies with wall sub-cooling and total pressure. The new correlation, covering two orders of magnitude in the condensation HTC, is valid for pressure ranging from 0.2 to $0.5 \mathrm{MPa}$, air mass fraction ranging from 0.1 to 0.8 and wall subcooling ranging from 10 to $70{ }^{\circ} \mathrm{C}$. Finally, he had made comparison with experimental data obtained by other investigators which shows that the new correlation is applicative for not only steam-air condensation but also steam-nitrogen and steamargon condensation, and it can be extended to larger scope of engineering applications.

\section{Governing equation and numerical algorithm}

A paper by Harlow et al. ${ }^{(35)}$ had an important impact on the development of numerical algorithms in multiphase flow modeling. The main ideas set forth in this paper are depicted below by considering a simplified model for onedimensional single-phase flow in a straight pipe. The differential equations for this model are:

- Mass conservation equation

$\frac{\partial \rho}{\partial t}+\frac{\partial \rho u}{\partial z}=0$

- Momentum conservation equation

$\frac{\partial \rho u}{\partial t}+\frac{\partial \rho u^{2}}{\partial z}=-\frac{\partial P}{\partial z}$

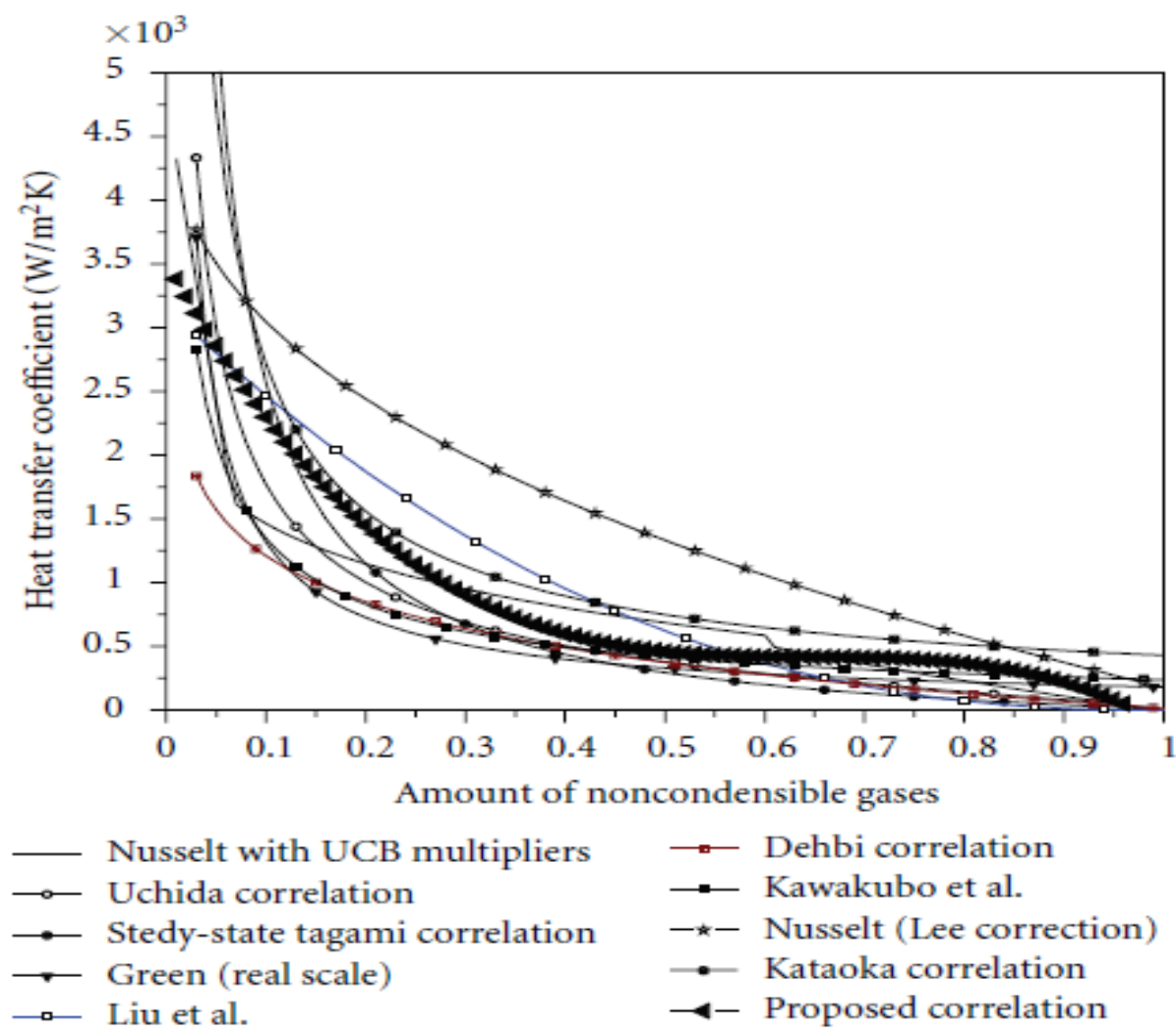

Figure (1): Various HTCs from the literature and proposed HTC based on curve fitting [34] 
Referring to the nodalization shown in Figure (2), casting mass conservation, Eqn. 3 into finite difference form, gives:

$$
\frac{\rho_{i}^{n+1}-\rho_{i}^{n}}{\Delta t}=-\frac{(\rho u)_{i+\frac{1}{2}}^{n+1}-(\rho u)_{i-\frac{1}{2}}^{n}}{\Delta z}
$$

where all terms are implicitly represented.

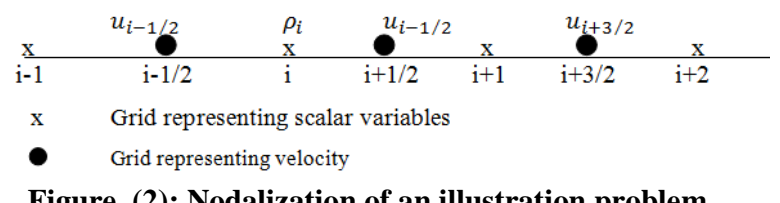

From the equation of state

$$
P_{i}^{n+1}=P_{i}^{n}+\left(\frac{\partial P}{\partial \rho}\right)_{i}^{n}\left(\rho_{i}^{n+1}-\rho_{i}^{n}\right)
$$

In Eqn.4, treating the pressure gradient term implicitly, and the momentum convection term explicitly, the finite difference from of the momentum conservation equation is derived as:

$$
\begin{gathered}
\frac{\left(\rho u^{2}\right)_{i+\frac{1}{2}}^{n+1}-(\rho u)_{i+\frac{1}{2}}^{n}}{\Delta t} \\
-\frac{P_{i+1}^{n+1}-P_{i}^{n+1}}{\Delta z}-\frac{\left(\rho u^{2}\right)_{i+1}^{n}-\left(\rho u^{2}\right)_{i}^{n}}{\Delta z}
\end{gathered}
$$

Using upwinding interpolation on the momentum convection term gives:

$$
\begin{gathered}
\left(\rho u^{2}\right)_{i+1}^{n}=\quad(\rho u)_{i+1}^{n}= \\
\text { if }(\rho u)_{i+1}^{n} \geq 0 \\
\text { if }(\rho u)_{i+1}^{n}<0
\end{gathered}
$$

Velocities are calculated at nodes $i+1 / 2, i+3 / 2, \ldots$, Therefore, velocities at node $i+1, i+2, \ldots$ appearing in the above equations are represented by arithmetic average, i.e.,

$$
u_{i++1}^{n}=\frac{u_{i+\frac{1}{2}}^{n}+u_{i+\frac{3}{2}}^{n}}{2}
$$

Therefore, the discretized form of the momentum conservation equation, Eqn. 7, becomes

$(\rho u)_{i+\frac{1}{2}}^{n+1}=-\frac{\Delta t}{\Delta z}\left(P_{i+1}^{n+1}-P_{i}^{n+1}\right)+\Delta t R_{i+\frac{1}{2}}^{n}+(\rho u)_{i+\frac{1}{2}}^{n}$

From Eqn.6, one gets

$$
\rho_{i}^{n+1}=\rho_{i}^{n}-\frac{P_{i}^{n}}{\left\{\frac{\delta P}{\delta \rho}\right\}_{i}^{n}}+\frac{P_{i}^{n+1}}{\left\{\frac{\delta P}{\delta \rho}\right\}_{i}^{n}}
$$

Substituting Eqns. 8 through 9 into Eqn. 5, one gets:

$a_{i} P_{i}^{n+1}+b_{i} P_{i+1}^{n+1}+c_{i} P_{i-1}^{n+1}=d_{i}$

The governing equations can be easily solved to find velocities, temperature and pressure using the TDMA technique. The solution procedures can be summarized as follows:

1. Guess pressure and velocities, or use these parameters obtained in pervious iteration.

2. Solve Eqn. 10 to fined pressures.

3. Find $\rho_{i}^{n+1}$ based on the pressures obtained in the previous iteration.

4. From Eqn. 8, find $u_{i}^{n+1 / 2}$.

The above procedure is repeated until convergence is reached.

The same authors later on extended their work to two-phase flow modeling (Harlow et al. ${ }^{(36)}$ ). The idea of their solution procedure can be illustrated by the following conservation equations which govern the behavior of the phases, in absence of interphase mass transfer, heat transfer and wall friction. An example is a one-dimensional problem, as investigated by Kurosaki et al. ${ }^{(37)}$.

- Mass conservation equation

$\frac{\delta}{\delta t}\left(\alpha_{1}\right)+\frac{\delta}{\delta z}\left(\alpha_{1} v_{1}\right)=0$

$\frac{\delta}{\delta t}\left(\alpha_{2}\right)+\frac{\delta}{\delta z}\left(\alpha_{2} v_{2}\right)=0$

- Momentum conservation equations

$$
\begin{aligned}
& \frac{\delta}{\delta t}\left(\alpha_{1} v_{1}\right)+\frac{\delta}{\delta z}\left(\alpha_{1} v_{1}^{2}\right)=-\frac{\alpha_{1}}{\rho_{1}} \frac{\delta P}{\delta z}+\left(v_{2}-v_{1}\right) F \\
& \frac{\delta}{\delta t}\left(\alpha_{2} v_{2}\right)+\frac{\delta}{\delta z}\left(\alpha_{2} v_{2}^{2}\right)=-\frac{\alpha_{2}}{\rho_{2}} \frac{\delta P}{\delta z}+ \\
& \left(v_{1}-v_{2}\right) F-\alpha_{2}\left(1-\frac{\rho_{1}}{\rho_{2}}\right) \mathrm{g}
\end{aligned}
$$

Control volume on which momentum equations are integrated 


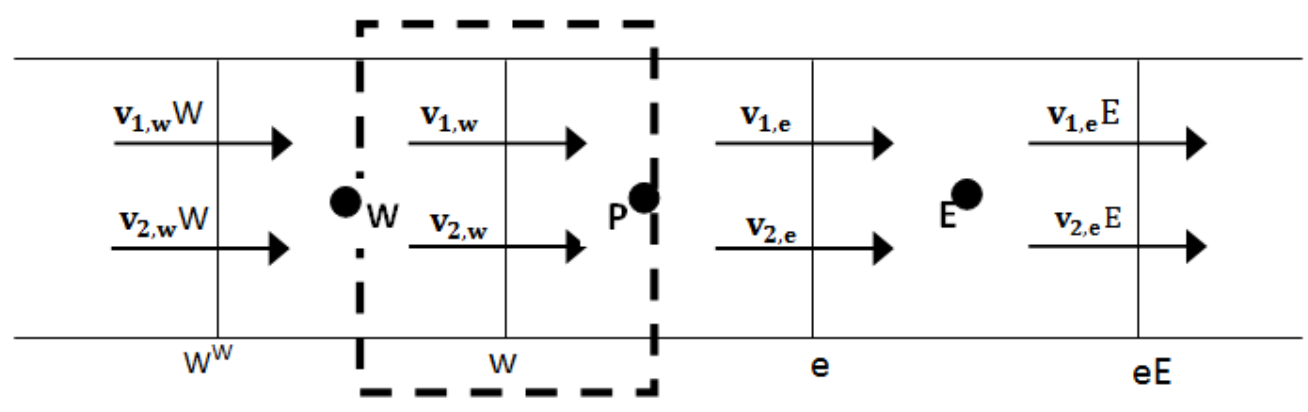

Figure (3): Nodalization of a single one-dimensional two-phase problem

Integrating Eqn. 12 on a control volume shown in Figure (3) and treating convection term explicitly gives:

$$
\left(\propto_{2, P}^{n+1}-\propto_{2, P}^{n}\right) \Delta z+\left[\left(\propto_{2} v_{2}\right)_{e}^{n}-\left(\propto_{2} v_{2}\right)_{w}^{n}\right] \Delta t=0
$$

Using up-winding interpolation for convection term, one gets:

$$
\left(\propto_{2} v_{2}\right)_{e}^{n}=\left\{\begin{array}{cccc}
\propto_{2, P}^{n} & v_{2, e}^{n} & \text { If } & v_{2, e}^{n} \geq 0 \\
\propto_{2, e}^{n} & v_{2, e}^{n} & \text { If } & v_{2, e}^{n}<0
\end{array}\right.
$$

As noted, all variables on the right of the above equation are found from pervious time step, therefore, from this equation, new time step volume fractions at each node are obtained.

Integrating Eqn. 11 on the control volume shown in Figure (3) and treating convection terms implicitly, gives:

$$
\left(\propto_{1, P}^{n+1}-\propto_{1, P}^{n}\right) \Delta z+\left[\left(\propto_{1} v_{1}\right)_{e}^{n+1}-\left(\propto_{1} v_{1}\right)_{w}^{n+1}\right] \Delta t=0
$$

Integrating Eqn.13 on a control volume shown in Figure (3) and treating terms such as pressure gradient $\partial P / \partial z$ and friction term $\left(v_{2}-v_{1}\right) \mathrm{F}$ implicitly, and all other terms explicitly, gives:

$$
\begin{aligned}
{\left[\left(\propto_{1} v_{1}\right)_{w}^{n+1}-(\right.} & \left.\left(\propto_{1} v_{1}\right)_{e}^{n}\right] \Delta z \\
& +\left[\left(\propto_{1} v^{2}\right)_{P}^{n}-\left(\propto_{1} v_{1}^{2}\right)_{W}^{n}\right] \Delta t \\
& =\frac{\left(\propto_{1}\right)_{w}^{n+1}}{\rho_{1, w}} \frac{P_{P}^{n+1}-P_{w}^{n+1}}{\Delta z} \Delta z \Delta t \\
& +\left(v_{2, w}^{n+1}-v_{1, w}^{n+1}\right) F \Delta z \Delta t
\end{aligned}
$$

Convection terms in the above equation are obtained using up-winding interpolation. Thus:

$$
\begin{aligned}
& \left(\propto_{1} v_{1}^{2}\right)_{p}^{n}=\left(\propto_{1} v_{1}\right)_{w}^{n}\left\langle v_{1, P}^{n} \gg\right. \\
& -\left(\propto_{1} v_{1}\right)_{e}^{n} \ll-v_{1, P}^{n} \gg
\end{aligned}
$$

$\left(\propto_{1} v_{1}^{2}\right)_{W}^{n}=\left(\propto_{1} v_{1}\right)_{w, W}^{n} \ll v_{1, W}^{n} \gg-\left(\propto_{1} v_{1}\right)_{w}^{n}$ $\left\langle-v_{1, W}^{n} \gg\right.$

where, velocities $v_{1, P}$ and $v_{2, W}$ are calculated by arithmetic average of $v_{e}$ and $v_{w}$.

Substituting Eqns. 18 and 19 into Eqn. 17, one gets:

$$
\begin{gathered}
\left(\propto_{1, w}^{n+1}+F \Delta t\right) v_{1, w}^{n+1}-F \Delta t v_{2, w}^{n+1}=G_{2}^{n}-\frac{\alpha_{1, w}^{n+1}}{\rho_{1, w}} \\
\frac{\Delta t}{\Delta z}\left(P_{P}^{n+1}-P_{W}^{n+1}\right)
\end{gathered}
$$

Similarly, the discretized form of Eqn. 14 becomes:

$$
\begin{gathered}
\left(\propto_{2, w}^{n+1}+F \Delta t\right) v_{2, w}^{n+1}-F \Delta t v_{1, w}^{n+1}=G_{1}^{n}-\frac{\alpha_{2, w}^{n+1}}{\rho_{2, w}} \\
\frac{\Delta t}{\Delta z}\left(P_{P}^{n+1}-P_{W}^{n+1}\right)
\end{gathered}
$$

In Eqn. 20 and 21, $\propto_{2, \mathrm{w}}^{\mathrm{n}+1}$ is replaced with $\propto_{2, \mathrm{w}}^{\mathrm{n}+1}=$ $\left(\propto_{2, \mathrm{~W}}^{\mathrm{n}+1}+\propto_{2, \mathrm{P}}^{\mathrm{n}+1}\right) / 2$. The parameters $\propto_{2, \mathrm{~W}}^{\mathrm{n}+1}$ and $\propto_{2, \mathrm{P}}^{\mathrm{n}+1}$ are obtained from solution of Eqn. 21 when applied to all grid points. The parameters $\propto_{1, \mathrm{w}}^{\mathrm{n}+1}$ is obtained from the relation $\propto_{1, \mathrm{w}}^{\mathrm{n}+1}+\propto_{2, \mathrm{w}}^{\mathrm{n}+1}=1$. Both of these parameters are thus considered Known. At this point unknown parameters in Eqn. 20, 21 are $\mathrm{P}_{\mathrm{P}}^{\mathrm{n}+1}, \mathrm{P}_{\mathrm{W}}^{\mathrm{n}+1}, \mathrm{v}_{1, \mathrm{~W}}^{\mathrm{n}+1}, \mathrm{v}_{2, \mathrm{~W}}^{\mathrm{n}+1}$. These two equations give:

$$
\begin{aligned}
& v_{1, w}^{n+1}=\xi_{1, w}^{n}\left(P_{P}^{n+1}-P_{W}^{n+1}\right)+\eta_{1, w}^{n} \\
& v_{2, w}^{n+1}=\xi_{2, w}^{n}\left(P_{P}^{n+1}-P_{W}^{n+1}\right)+\eta_{2, w}^{n}
\end{aligned}
$$

Using the guessed pressure (at the beginning of iteration), velocity $\mathrm{v}_{1}$, and $\mathrm{v}_{2}$ at each grid point can be found from Eqns. 22 and 23. These velocities cannot satisfy the mass conservation equations, and if they inserted into the mass conservation 
equation, right side will not be equal to zero. Assume this mass error is $D_{P}$,

$$
\begin{gathered}
\mathrm{D}_{\mathrm{P}}=\left(\propto_{1, P}^{n+1}-\propto_{1, P}^{n}\right) \Delta z+\left[\left(\propto_{1} v_{1}\right)_{e}^{n+1}-\right. \\
\left.\left(\propto_{1} v_{1}\right)_{w}^{n+1}\right] \Delta t
\end{gathered}
$$

Now, we can find a new pressure so that mass conservation is satisfied at each control volume. That is, find an improved pressure by iteratively solving Eqn. 24, to make $D_{P}=0$. For this, the Newton-Raphson model is used.

Harlow et al.[38]subsequently extended the above algorithm to three-phase flow problems. In the solution process, the effects of pressures at neighboring grid points are neglected. This disadvantage has been overcome in TRAC[4] and RELAP[6] codes. In these algorithms, a system of equations in terms of the new time step pressures at all grid points is directly solved.

The aforementioned shortcoming was noticed by Stewart [39], who developed a two-fluid modeling algorithm for transient boiling channel flow. His work can be consider essentially as an extension and improvement of the aforementioned work by Harlow et al.[36], the major improvement being the direct solution for coupled pressures.

A different algorithm for multi-phase flow modeling was derived by Rivard and Torrey [40] in their effort for the development of the K-FIX computer program. In the algorithm used in this code, in order to cast all conservation equations into discretized forms, all terms except for convective terms in momentum equations are implicitly treated. The resulting nonlinear algebraic equations are solved by Gauss-seidel point iteration method. The coupling between velocity and pressure is treated similar to the work by Harlow et al.[36]. Thus, when treating coupling between pressure and velocity in a node, the effects of pressure at neighboring grid points are neglected. Consequently, convergence in this code is slow.

Mahaffy [41] proposed an important algorithm called Stability Enhancing Two Step (SETS) method. In this algorithm at each time step the variables are updated in two steps. In the first step, the new time step pressure and velocity are obtained. The remaining variables are subsequently calculated in the second step, using the pressure and velocities obtained in the first step. This algorithm is used in various versions of TRAC code.

The algorithm in the widely used computer code RELAP5/MOD3 is efficient and robust in one dimensional multiphase flow modeling, and is different from all the algorithm reviewed above. The main difference between the algorithm in RELAP5/MOD3 code and other algorithms is the way coupling between velocity and pressure is related. In RELAP5/MOD3 code, the new timestep pressures are directly calculated. The procedure for calculating the new pressures does not involve the simultaneous iterative solution of any other variables. This makes the algorithm robust and efficient, but limited to onedimensional modeling.

These numerical algorithm were all developed by nuclear industry community, and they all belong to the semi-implicit methods. An important algorithm, not directly related to the nuclear community, is the Interphase Slip Algorithm (IPSA), proposed by Spalding [42]. This algorithm has been incorporated in a widely used commercial code called PHOENICS [43]. The algorithm is an extension of the Semi-Implicit Method for Pressure Linked Equations (SIMPLE)[44], an efficient algorithm in single-phase flow modeling.

Although the IPSA algorithm is a fully implicit solution procedure, the equations are solved by one, as they are in single-phase modeling [44]. Adding more equations, as is required in multiphase flow modeling, does not add any difficulties due to the aforementioned one-nature. This algorithm has great potential in dealing with multiphase flow modeling. Previously published multiphase applications include the modeling of two-dimensional, steady state, two-phase flows occurring in certain environmental processes [45]; steady state, three-phase flow and heat transfer in steam generators [46]; unsteady three-dimensional two-phase flow and heat transfer in steam generators [47]; and the stratified two-phase flow in channels [48]. 


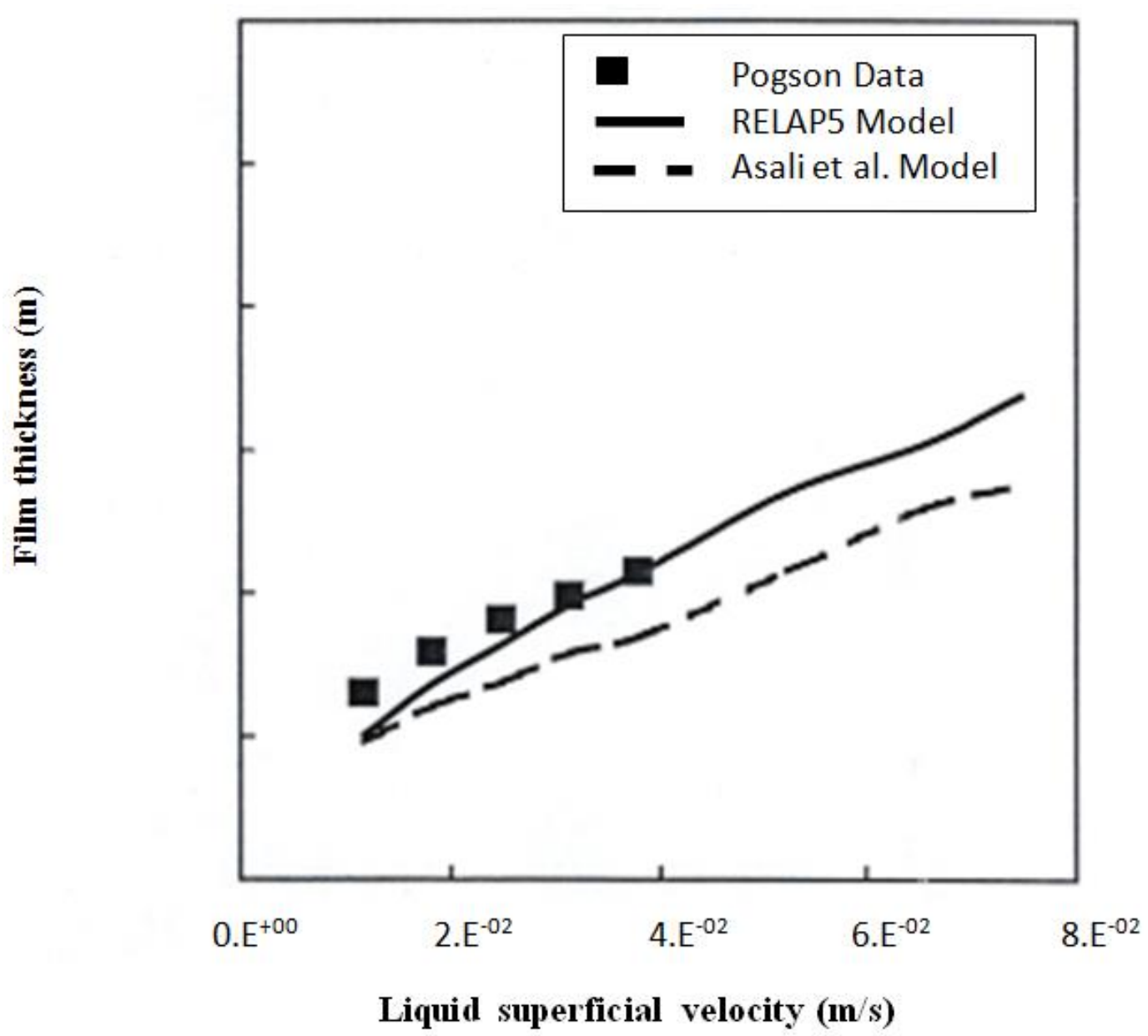

Figure (4): Comparison of the RELAP5 model prediction with the data of Pogson and the model of Asali at jg-22.43 m/s

The crucial step in numerical modeling of fluid flow problems is the treatment of the coupling between pressure and velocity. In conservation equations, we do not have an equation specifically for pressure. Pressure appears in momentum conservation equations, however. In order to solve numerically for pressure, an equation with pressure as unknown is obtained from mass and momentum conservation equations in some algorithms such as in the (SIMPLE) [44] and IPSA [43] algorithms. In other algorithms, it is found from mass, energy and momentum equations. Examples of the latter category of algorithms include the algorithms used in TRAC and RELAP5 codes. In the process of derivation of an equation for pressure, the effects of some dependent variables on pressure must be neglected in all of these algorithms.

Predictions made by RELAP5/MOD3 model are depicted in Figure (4). These results were obtained by dividing the test section of Pogston et al.[49] into 10 fluid volumes, each $1.83 \mathrm{~cm}$ in length. The RELAP5/MOD3 model as shown in figure predicts the liquid film thickness more significant than that of Asali et al.[50].

\section{Conclusion}

It should be noted that due to the complicated nature of conservation equations in multiphase flow problems, and due to the lack of a comprehensive theory for nonlinear differential equations, numerical errors associated with the above mentioned algorithms are expected. The only reliable way to investigate the accuracy of algorithms is to compare their numerical predictions with data obtained in experiments, which involves few well-understood physical processes. An important difficulty in performing such validations is the considerable uncertainty associated with the mathematical formulation of 
physical processes in multiphase flow problems, such as correlations to calculate friction and heat transfer coefficient. Therefore, it is difficult to make a general quantitative comparison between these algorithms.

\section{Nomenclature}

$\begin{array}{ll}D_{P} & \text { Mass error } \\ F, g & \text { Liquid and gas interfacial drag } \\ \begin{array}{l}\text { coefficients } \\ h\end{array} & \text { Heat transfer coefficient, } \\ \left(\mathrm{W} / \mathrm{m}^{2} . \mathrm{K}\right) & \\ i & \text { ith iteration level } \\ m_{g} & \text { Mass of non- condensable gases } \\ m_{s} & \text { Mass of steam } \\ n & \text { non-condensable gases } \\ P & \text { Pressure }\left(\mathrm{N} / \mathrm{m}^{2}\right) \\ R & \text { Channel radius (m) } \\ T & \text { Temperature (K) } \\ t & \text { time } \\ u & \text { Velocity (m/s) } \\ v & \text { Velocity component (m/s) } \\ v_{1}, v_{2} & \text { Velocity at each grid point } \\ w & \text { Wall } \\ z & \text { Axial coordinate (m) } \\ \text { Greek symbols } & \\ \rho & \\ \alpha & \text { density } \\ \partial t & \text { Void fraction } \\ c y c l e & \text { time increment per calculation } \\ & \end{array}$

\section{References}

1-Nusselt, W., Die Oberflachen-Kondensation des Wasserdampfes, Zeitschrift des Vereines deutscher Ingenieure, 60, 541-546, 569-575, (1916).

2-Uchida, H., Oyama, A., Togo, Y., Evaluation of postincident cooling systems of light-water power reactors. In: Proceedings of International Conference on Peaceful Uses of Atomic Energy, vol. 13, pp. 93102, (1965).

3-Tagami, T., Interim Report on Safety Assessments and Facilities Establishment Project for June 1965, No. 1. Japanese Atomic Energy Research Agency, (1965).

4-D.D. Taylor, "TRAC-DBI/MODI， An Advanced Best-Estimated Computer Program for Boiling Water Reactor Transient", U.S. Nuclear Commission Report, NUREG/CR-3633, (1984).
5-J.H.McFadden,"RETRAN-03, A Program for Transient Thermal Hydraulic Analysis of Computer Fluid Flow System", Electric Power Research Institute Report EPRI NP-7550, California-(1992).

6-V.H. Ransom,"RELAP5/MOD2 Code Manual",1,NUREG/CR-4312,EGG-2396,(1985).

7-K.E Carlson, " RELAP5/MOD3 Code Manual",1,NUREG/CR-5535,EGG-2596,(1996).

8-R. G. Gido and A. Koestel, "Containment Condensing Heat Transfer", 2nd Int'l Topical Meeting on Nuclear Reactor Thermal Hydraulics (NURETH-2), 1983, pp 1111-1119.

9-Dehbi, A.A., 1990. Analytical and Experimental Investigation of the Effects of Non-condensable Gases on Steam Condensation Under Turbulent Natural Convection Conditions. Ph.D. dissertation, M.I.T. Department of Nuclear Engineering.

10-M. L. Corradini, "Turbulent Condensation on a Cold Wall in the Presence of a Non-condensable Gas", Nuclear Technology, Vol. 64, 1984, pp. 186-195.

11-P. F. Peterson, V. E. Schrock and T. Kageyama, "Diffusion Layer Theory for Turbulent Vapor condensation with Non-condensable Gases", ASME Journal of Heat Transfer, Vol. 115, 1993, pp. 9981003.

12-Mills, A.F., 1994. In: Irwin (Ed.), Heat Transfer. USA.

13-Kang, H.C., Kim, M.H., 1994. Effect of noncondensable gas and wavy interface on the condensation heat transfer in a nearly horizontal plate. Nucl. Eng. Des. 149, 313-321.

14-Kim, M.H., Corradini, M.L., 1990. Modeling of condensation heat transfer in a reactor containment. Nucl. Eng. Des. 118, 193-212.

15-Karapantsios, T.D., Kostoglou, M., Karabelas, A.J., 1995. Local condensation rates of steam-air mixtures in direct contact with a falling liquid film. Int. J. Heat Mass Transfer 38 (5), 779-794.

16-Koh, J.C.Y., Sparrow, E.M., Hartnett, J.P., 1961. The two-phase boundary layer in laminar film condensation. Int. J. Heat Mass Transfer 2, 69-82.

17-Park, S.K., Kim, M.H., Yoo, K.J., 1997. Effects of a way interface on steam-air condensation on a vertical surface. Int. J. Multiphase Flow 23 (6), 1031-1042.

18-Fox, R.J., Peterson, P.F., Corradini, M.L., Pertensteiner, A.P., 1997. Free convective condensation in a vertical enclosure. Nucl. Eng. Des. 177, 71-89.

19-Herranz, L.E., Anderson, M.H., Corradini, M.L., 1998. A diffusion layer model for steam condensation within the AP600 containment. Nucl. Eng. Des. 183, 133-150.

20-Mu noz-Cobo, J.L., Herranz, L., Sancho, J., Tkatchenko, I., Verdu' , G., 1996. Turbulent vapor condensation with non-condensable gases in vertical tubes. Int. J. Heat Mass Transfer 39 (15), 3249-3260.

21-Green, J., Almenas, K., 1996. An overview of the primary parameters and methods for determining

Arab J. Nucl. Sci. \& Applic. Vol. 53, No. 1 (2020) 
condensation heat transfer to containment structures. Nucl. Saf. 37, 26-47.

22-Murase, M., Kataoka, Y., Fujii, T., 1993. Evaporation and condensation heat transfer with noncondensable gas present. Nucl. Eng. Des. 141, 135143.

23-Bunker, R.S., Carey, V.P., 1986. Modeling of turbulent condensation heat transfer in the boiling water reactor primary containment. Nucl. Eng. Des. 91, 297-304.

24-Malet, J., Porcheron, E., Vendel, J., 2005. Filmwise condensation applied to containment studies: conclusions of the TOSQAN air-steam condensation tests. In: NURETH-11 (11th International Topical Meeting on Nuclear Reactor Thermal-Hydraulics), Avignon, France.

25-Whitley, R., Chan, C., Okrent, D., 1976. On the analysis of containment heat transfer following on LOCA. Ann. Nucl. Eng. 3, 515-525.

26-Slegers, L., Seban, R.A., 1970. Laminar film condensation of steam containing small amounts of air. Int. J. Heat Mass Transfer 13, 1941-1947.

27-Hampson, H., 1951. The condensation of steam on a metal surface. In:Proceedings of General Discussion on Heat Transfer. Institution of Mechanical Engineers, pp. 58-61.

28-Meisenburg, J., Boarts, R.M., Badger, W.L., 1935. The influence of small concentrations of air in steam on the steam film coefficient of heat transfer. Trans. Am. Inst. Chem. Eng. 31, 622-637.

29-Huhtiniemi, I.K., Corradini, M.L., 1993. Condensation in the presence of Non-condensable gases. Nucl. Eng. Des. 141, 429-446.

30-Arijit Ganguli a, A.G. Patel b, N.K. Maheshwari b, A.B. Pandit a," Theoretical Modeling of Condensation of Steam Outside Different Vertical Geometries (tube, flat plates) In The Presence of Non-condensable Gases Like Air and Helium", Nuclear Engineering and Design 238 (2008) 23282340.NRC, 1956a. United States code of federal regulations 10 CFR part 50.

31-Mehdi Dehjouriana, Reza Sayareh, Mohammad Rahgoshay, Gholamreza Jahanfarnia, and Amir Saied Shirani" Investigation of a Hydrogen Mitigation System During Large Break Loss-Of-Coolant Accident for a Two-Loop Pressurized Water Reactor" Nuclear Engineering and Technology 48 (2016) $1174-1183$.

32-Xiaomin Wu, Fuqiang Chu, Yu Zhu, Qianyu Li, "Vapor free convection film condensation heat transfer in the presence ofnon-condensable gases with smaller molecular weights than the vapor. "Applied Thermal Engineering 130 (2018) 16111618.
33-Guangming Fan a, $\Uparrow$, Pan Tong b, Zhongning Sun a, Yitung Chen, "Development of a new empirical correlation for steam condensation rates in the presence of air outside vertical smooth tube", Annals of Nuclear Energy 113 (2018) 139-146.

34-Pavan K. Sharma, B. Gera, R. K. Singh, and K. K. Vaze, "Computational Fluid Dynamics Modeling of Steam Condensation on Nuclear Containment Wall Surfaces Based on Semiempirical Generalized Correlations, Science and Technology of Nuclear Installations Volume 2012, Article ID 106759, 7 pages 2012.

35-F.H. Harlow and A.A. Amsden; Journal of Computational Physics; 8, 197 (1971).

36-F.H. Harlow and A.A. Amsden; Journal of Computational Physics; 17, 19 (1975).

37-Y. Kurosaki and D.B. Spalding, "The Second MultiPhase Flow and Heat Transfer Symposium", Miami, (1979).

38-F.H. Harlow and A.A. Amsden; Journal of Computational Physics; 18, 440 (1975).

39-H.B. Stewart; Journal of Computational Physics; 30, 61 (1971).

40-W.C. Rivard and M.D. Torrey, "K-FIX: A Computer Program For Transient, Two-Dimensional, TwoFluid Flow", Los Alamos National Lab., LAUUREG-6623, (1977).

41-J.H. Mahaffy; J. of Comp. Physics; 46, 329 (1982).

42-D.B. Spalding, Hemisphere, Washington, (1977).

43-H.I. Rosten and D.B. Spalding, "PHONICS Beginner's Guide and User's Manual", CHAM Technical Report TR/100, (1986).

44-S.V. Patanker, "Numerical Heat Transfer and Fluid Flow", McGraw-Hill Book Company, (1980).

45-D.B. Spalding, "Developments in the IPSA Procedure for Numerical Computation of Multiphase Flow Phenomena With Interphase Slip, Unequal Temperature, etc, In Numerical Properties and Methodologies in Heat Transfer", Hemisphere, Washington, (1983).

46-W.M. Pun, D.B. Spalding, H. Rosten, and U. Svensson; ICHMT Seminar; Dubrovnik, (1978).

47-N.C.G. Markatos, A. Moult, P.J. Phelps and D.B. Spalding, ICHMT Seminar; Dubrovnik, (1978).

48-A.K. Singhal and D.B. Spalding, "Multiphase Transport: Fundamental, Reactor Safety, Application", ", Hemisphere, Washington, (1980).

49-A.H.A. Baghdadi, H. Rosten, A.K. Singhal, D.G. Tatchell and D.B. Spalding, ICHMT Seminar; Dubrovnik, (1978).

50-J.T. Pogson, J.H. Roberts and P.J. Waibler; J. Heat Transfer; 92651 (1970).

51-J.C. Asali, T.J. Hanratty and P. Andreussi; AICHE.; 31, 895 (1985). 